\title{
DUKUNGAN KELUARGA, PENGETAHUAN, DAN PERSEPSI IBU SERTA HUBUNGANNYA DENGAN STRATEGI KOPING IBU PADA ANAK DENGAN GANGGUAN Autism Spectrum Disorder (ASD)
}

Family Support, Mother's Knowledge and Perception of ASD, and Its Correlation with Coping Strategy of Mothers with Autism Spectrum Disorder (ASD) Children

\author{
LIA MILYAWATI ${ }^{1}$, DWI HASTUTI ${ }^{2 *}$ \\ ${ }^{1}$ Program Studi Gizi Masyarakat dan Sumberdaya Keluarga, Fakultas Pertanian, \\ Institut Pertanian Bogor, Kampus Dramaga, Bogor 16680 \\ ${ }^{2}$ Staf Pengajar Departemen Ilmu Keluarga dan Konsumen, Fakultas Ekologi \\ Manusia, Institut Pertanian Bogor, Jalan Lingkar Kampus IPB Dramaga, \\ Bogor 16680
}

\begin{abstract}
The objective of study was to understand family support, mother's knowledge and perception of ASD and its association with coping strategy of mothers with ASD children. The study used a cross-sectional study design and conducted at Sekolah Khusus AL-IHSAN in Tangerang and in Cilegon, Banten. The samples of the study were 31 mothers with ASD children who were participated at AL-IHSAN and were available to be interviewed. The study conducted at February until May 2008 which included data collecting, data processing, and data analyzing. Instrumen used in the study was a modification of Coping Health Inventory for Parents (CHIP) by McCubbin and Patterson (1987). Data analyzing used was descriptive statistics, paired sample T-test, Rank-Spearman correlation, and Chi-Square. Result of the study showed that family support was considered as low $(45,2 \%)$ and high or very high $(54,8 \%)$. Mother's knowledge mostly good, which classified as moderate and high (93,5\%), while those classified as low was only 6,5\%. In term of mother's perception there were $45,2 \%$ mothers who still had negative perception toward ASD child. There was differences in term of coping mechanism strategy which was mostly to maintain family stability, optimism and cooperation at present, while before were mostly to seek assistance for medical treatment. The younger age of mothers and fathers, the stronger family support they received. Mother's perception of ASD children tend to be positive when the age of ASD children is younger and the length of therapy is shorter. The characteristics of family, family support, mother's knowledge, and perception of ASD children had no significant correlation with coping strategy used by mothers as their effort to reduce some pressures in taking care of ASD children.
\end{abstract}

\section{Key words: autism, coping strategy, family support, mother's knowledge} and perception

\section{PENDAHULUAN}

Autism Spectrum Disorder (ASD) adalah gangguan perkembangan terutama dalam berperilaku, yang secara umum disebabkan oleh kelainan struktur otak atau fungsi otak. ASD ini terlihat sebelum anak berusia tiga tahun dan dapat diketahui dari interaksi sosial dan komunikasi yang terbatas dan berulangulang.
Penyandang ASD semakin meningkat di seluruh dunia. Pada tahun 2006 diperkirakan prevalensi jumlah penyandang ASD 1:100 kelahiran (Kelana \& Elmy 2007). Di Indonesia hingga saat ini penyandang ASD belum diketahui secara pasti jumlahnya, akan tetapi diperkirakan lebih dari 400.000 orang (Kelana \& Elmy 2007).

Halroyd dan Mc Arthur (1976) dalam Tobing (2004) menyatakan bahwa ibu 
dengan anak ASD memiliki tingkat stres yang lebih tinggi dibandingkan dengan ibu yang memiliki anak Down Syndrome. Selain itu, orang tua dengan anak ASD memiliki stres yang lebih besar dibandingkan orang tua dengan anak yang menderita kesulitan belajar (Konstantareas 1992 dalam Tobing 2004) dan retardasi mental (Donovan 1988 dalam Tobing 2004). Stres tersebut dapat berpengaruh pada peran ibu terutama dalam merawat, mengasuh, dan mendidik anak.

Strategi koping yang efektif diharapkan mampu mengurangi stres ibu dalam menghadapi anak ASD sehingga dapat melaksanakan peran pengasuhannya dengan baik. Strategi koping keluarga yang dikembangkan oleh McCubbin dan Patterson (1987) yaitu Coping Health Inventory for Parents (CHIP). Strategi koping tersebut dibedakan ke dalam tiga pola yaitu Pola I mempertahankan keutuhan keluarga, kerjasama, dan situasi optimis; Pola II memelihara dukungan sosial, kepercayaan diri, dan stabilitas psikologis; Pola III memahami situasi medis melalui komunikasi antar orang tua dan konsultasi dengan staf medis (McCubbin \& Thompson 1987).

Penelitian ini dilakukan untuk mengetahui strategi koping ibu pada anak dengan gangguan Autism Spectrum Disorder (ASD), termasuk bentuk dukungan keluarga, pengetahuan, dan persepsi ibu terhadap anak ASD.

Tujuan khusus dari penelitian ini adalah: (1) mengidentifikasi karakteristik anak dan karakteristik keluarga dari anak ASD; (2) mengidentifikasi dukungan keluarga, pengetahuan, dan persepsi ibu terhadap anak ASD; (3) menganalisis perbedaan strategi koping yang digunakan ibu pada saat ini dan pada saat pertama mengetahui anak mengalami gangguan ASD; (4) menganalisis hubungan antara karakteristik keluarga dan anak dengan dukungan keluarga, pengetahuan, dan persepsi ibu terhadap anak ASD; dan (5) menganalisis hubungan antara karakteristik keluarga, dukungan keluarga, pengetahuan, dan persepsi ibu terhadap anak ASD dengan strategi koping yang digunakan saat ini.

\section{METODE}

\section{Desain, Tempat, dan Waktu}

Desain penelitian yang digunakan adalah cross sectional study. Penelitian ini dilakukan di Sekolah Khusus Al-Ihsan Cilegon dan Sekolah Khusus Al-Ihsan Tangerang. Lokasi ini ditentukan secara purposive. Penelitian dilakukan mulai bulan Februari hingga Mei 2008 yang meliputi pengumpulan, pengolahan, serta analisis data.

\section{Teknik Penarikan Contoh}

Kriteria contoh dalam penelitian ini adalah ibu yang memiliki anak ASD yang sedang melakukan terapi di Sekolah Khusus Al-Ihsan Cilegon dan Sekolah Khusus Al-Ihsan Tangerang dan bersedia untuk diwawancarai. Jumlah anak ASD di Sekolah Khusus Al-Ihsan Cilegon adalah 20 anak dan di Sekolah Khusus Al-Ihsan Tangerang adalah 39 anak. Jumlah anak dari kedua tempat tersebut adalah 59 anak ASD. Jumlah contoh yang bersedia diwawancarai dan digunakan sebagai contoh dalam penelitian ini adalah 31 ibu dan anaknya.

\section{Jenis dan Pengumpulan Data}

Data yang dikumpulkan berupa data primer dan data sekunder. Data primer diperoleh melalui wawancara langsung dengan ibu dari anak ASD dengan menggunakan kuesioner. Data primer meliputi karakteristik anak ASD (usia dan jenis kelamin), karakteristik keluarga (usia contoh dan suami, lama pendidikan contoh dan suami, jenis pekerjaan contoh dan suami, besar dan tipe keluarga, pendapatan keluarga), pengetahuan contoh mengenai ASD, dukungan keluarga, persepsi contoh terhadap ASD, dan strategi koping. Data sekunder yaitu mengenai keadaan umum Sekolah Khusus Al-Ihsan meliputi profil sekolah, jumlah terapi, identitas dan jumlah anak ASD yang diperoleh dari Tata Usaha Yayasan.

\section{Pengolahan dan Analisis Data}

Data primer yang diperoleh diolah dengan menggunakan program komputer Microsoft Excel dan SPSS (Statistical Package for Social Sciences) 10.0 for Windows. Proses pengolahan mencakup langkah-langkah editing, coding, scoring, entry, cleaning, dan analisis data. 
Pengkategorian variabel dukungan keluarga dan persepsi didasarkan pada median skor kelompok. Pengukuran variabel strategi koping contoh berdasarkan pada strategi koping untuk orang tua atau CHIP dari McCubbin dan Thompson (1987) yang telah disesuaikan. Penentuan kategori kecenderungan pola koping yang digunakan contoh berdasarkan pada persentase skor jawaban untuk masingmasing pola koping. Persentase skor terbesar dari ketiga pola koping akan menentukan kecenderungan pola koping yang digunakan contoh dalam merawat anak ASD.

Seluruh data primer yang terkumpul kemudian dianalisis secara deskriptif. Uji statistik yang digunakan adalah paired sample T-test, korelasi Spearman dan chi-square. Paired sample T-test untuk mengetahui perbedaan antara strategi koping contoh saat pertama mengetahui anak menderita ASD dan saat ini. Uji korelasi Spearman digunakan untuk mengetahui hubungan antara karakteristik anak dan keluarga dengan pengetahuan contoh, dukungan keluarga, dan persepsi contoh terhadap anak ASD. Uji chi-square digunakan untuk melihat hubungan strategi koping contoh berdasarkan karakteristik keluarga, dukungan keluarga, pengetahuan, dan persepsi contoh terhadap anak ASD.

\section{HASIL DAN PEMBAHASAN}

\section{Karakteristik Anak}

Dumas dan Nielsen (2003) menyatakan bahwa peluang ASD pada anak lakilaki lebih besar dibandingkan dengan perempuan, yakni empat hingga lima kali lebih besar dibandingkan anak perempuan. Hasil penelitian menunjukkan bahwa $80,6 \%$ anak yang menderita ASD adalah laki-laki dan sisanya $19,4 \%$ adalah perempuan. Lebih dari separuh anak $(54,9 \%)$ yang menderita ASD berusia $\geq 96$ bulan dan hanya $3,2 \%$ yang berusia $36-$ 47 bulan. Hampir separuh anak ASD $(45,2 \%)$ telah diterapi selama 41-88 bulan dan $29 \%$ anak ASD telah diterapi selama $\geq 89$ bulan.

\section{Karakteristik Keluarga}

Usia. Sebanyak $61,3 \%$ ibu contoh berusia 31-40 tahun dengan rata-rata $38,0 \pm 5,73$ tahun. Sebesar $45,2 \%$ suami berusia 31-40 tahun dengan rata-rata $41,81 \pm 6,58$ tahun.

Lama Pendidikan. Tingkat pendidikan dapat mempengaruhi sikap dan perilaku individu dalam kehidupan seharihari. Lebih dari separuh ibu dan suami $(61,3 \%)$ menyelesaikan pendidikannya selama $\geq 15$ tahun atau setingkat dengan tamat perguruan tinggi. Rata-rata lama pendidikan ibu adalah $14,13 \pm 2,17$ tahun, sedangkan rata-rata lama pendidikan suami adalah $14,61 \pm 2,25$ tahun.

Jenis Pekerjaan. Jenis pekerjaan dapat menggambarkan besarnya pendapatan yang diperoleh anggota keluarga. Sebagian besar ibu $(74,2 \%)$ tidak bekerja atau sebagai ibu rumah tangga dan $25,8 \%$ ibu bekerja di luar rumah, sedangkan mayoritas suami bekerja sebagai pegawai swasta $(41,9 \%)$ dan sisanya bekerja sebagai wiraswasta $(35,6 \%)$, PNS $(16,1 \%)$, dan tentara $(3,2 \%)$ serta terdapat suami yang tidak bekerja $(3,2 \%)$ dikarenakan baru saja di PHK.

Besar dan Tipe Keluarga. Menurut Hurlock (1991) besar keluarga dikelompokkan menjadi tiga yaitu keluarga kecil ( $\leq 4$ orang), keluarga sedang (5-7 orang), dan keluarga besar ( $\geq 8$ orang). Sebesar $48,4 \%$ keluarga contoh merupakan keluarga sedang, $41,9 \%$ keluarga kecil, dan $9,7 \%$ keluarga besar. Selain itu, contoh yang memiliki tipe keluarga inti sebanyak $61,3 \%$ dan $38,7 \%$ memiliki tipe keluarga luas, dimana terdapat anggota keluarga lain yang juga tinggal bersama dengan keluarga inti (Hurlock 1991).

Pendapatan dan Alokasi Dana untuk Terapi ASD. Sebagian besar keluarga contoh merupakan keluarga dengan status sosial ekonomi yang tinggi. Sebanyak $35,5 \%$ ibu memiliki pendapatan keluarga sebesar $\mathrm{Rp} 2.510 .000,00$ Rp 5.000.000,00 per bulan, dan 19,4\% pendapatan keluarga sebesar Rp 5.100.000,00 - Rp 7.500.000,00 per bulan, serta $16,1 \%$ memiliki pendapatan lebih dari Rp 15 juta per bulan. Dana yang dialokasikan khusus untuk anak ASD lebih dari Rp 1,2 juta per bulan $(41,9 \%)$. Rata-rata dana yang dialokasikan keluarga adalah sebesar Rp 1.484.065,00 $\pm 1.323 .070,72$. Dana ini digunakan untuk membayar biaya terapis atau dokter, obat/suplemen, dan biaya pengasuhan anak ASD per bulan. 


\section{Dukungan Keluarga}

Dukungan keluarga adalah dukungan yang diberikan oleh keluarga baik keluarga inti maupun keluarga luas terhadap ibu yang memiliki anak ASD. Sebanyak 45,2\% ibu mendapatkan dukungan keluarga yang kurang kuat dan $41,9 \%$ ibu mendapatkan dukungan keluarga yang kuat dan hanya $12,9 \%$ ibu yang mendapatkan dukungan keluarga sangat kuat baik dari keluarga inti maupun keluarga luas.

\section{Pengetahuan Ibu Mengenai ASD}

Pengetahuan mengenai ASD ini penting untuk memahami anak ASD sehingga dapat melakukan perawatan dengan tepat. Hasil penelitian menunjukkan bahwa lebih dari separuh ibu $(51,6 \%)$ memiliki pengetahuan yang baik mengenai ASD dan 41,9\% ibu berpengetahuan sedang serta hanya $6,5 \%$ ibu yang memiliki pengetahuan kurang mengenai ASD. Sebagian besar ibu mengetahui bahwa ASD bukanlah suatu penyakit keturunan dan paling banyak penyandang ASD adalah anak laki-laki. Sebagian besar ibu memiliki pengetahuan yang baik mengenai makanan yang perlu dihindari oleh anak ASD. Oleh karena itu, para ibu melakukan diet bebas gluten (dari sumber makanan seperti gandum, oat, barley, makanan bertepung) dan casein (terdapat pada susu, mentega, keju, yoghurt, laktosa, whey, dll.) pada anak karena gluten dan casein dapat mengakibatkan perkembangan anak menjadi menurun.

\section{Persepsi Ibu terhadap Anak ASD}

Persepsi merupakan suatu hasil dari pengalaman seseorang terhadap objek, peristiwa atau keadaan. Oleh karena itu, setiap individu akan memiliki persepsi yang berbeda dalam menghadapi masalah anak ASD. Lebih dari separuh ibu $(54,8 \%)$ memiliki persepsi yang positif terhadap anak ASD dan $45,2 \%$ ibu yang memiliki persepsi negatif terhadap anak ASD.

\section{Strategi Koping Ibu}

Strategi koping merupakan suatu usaha atau upaya tingkah laku seseorang untuk menguasai, mengurangi, dan menoleransi tuntutan atau masalah yang sedang dihadapi. Lebih dari separuh ibu $(54,8 \%)$ pada saat ini menggunakan strategi koping mempertahankan keutuhan keluarga, kerjasama dan optimis (pola I) dan tidak ada yang menggunakan strategi koping dengan memelihara dukungan sosial, kepercayaan diri, dan stabilitas psikologis (pola II). Hasil penelitian yang dilakukan oleh Bristol (1984) dalam McCubbin dan Thompson (1987) pun mengungkapkan bahwa strategi koping yang dilakukan oleh ibu yang memiliki anak ASD adalah mempertahankan keutuhan keluarga, kerjasama, dan optimis (pola l). Sedangkan pada saat pertama kali ibu mengetahui anak menderita ASD, lebih dari separuh ibu (54,8\%) menggunakan strategi koping dengan memahami situasi dan komunikasi antar orang tua ASD dan dengan staf medis (pola III) (Tabel 1).

\section{Perbedaan Strategi Koping}

Berdasarkan hasil uji statistik menunjukkan bahwa terdapat perbedaan signifikan antara strategi koping saat pertama kali mengetahui anak ASD dan saat ini ( $p$-value=0,070, $\alpha=0,1)$ (Tabel 1). Diketahui bahwa pada saat pertama, strategi koping yang lebih banyak digunakan oleh ibu adalah strategi koping pola III. Dengan berkomunikasi

Tabel 1. Sebaran strategi koping ibu saat pertama mengetahui anak ASD dan saat ini

\begin{tabular}{|c|c|c|c|c|}
\hline \multirow{2}{*}{ Strategi Koping } & \multicolumn{2}{|c|}{ Saat Pertama } & \multicolumn{2}{|c|}{ Saat Ini } \\
\hline & $\mathbf{n}$ & $\%$ & $\mathbf{n}$ & $\%$ \\
\hline $\begin{aligned} \text { Pola I : } & \text { Mempertahankan keutuhan keluarga, } \\
& \text { kerjasama, dan optimis }\end{aligned}$ & 12 & 38,7 & 17 & 54,8 \\
\hline $\begin{aligned} \text { Pola II : } & \text { Memelihara dukungan sosial, kepercayaan diri, } \\
& \text { dan stabilitas psikologis }\end{aligned}$ & 2 & 6,5 & 0 & 0,0 \\
\hline 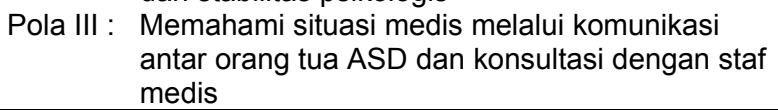 & 17 & 54,8 & 14 & 45,2 \\
\hline Total & 31 & 100,0 & 31 & 100,0 \\
\hline p-value & & 0,070 & & \\
\hline
\end{tabular}

Keterangan $:\left(^{*}\right)=$ signifikan pada taraf alpha 0,1 
dan berkonsultasi dengan orang yang memahami mengenai ASD ternyata dapat memperoleh informasi dan dapat saling bertukar pengalaman sehingga dapat memperluas wawasan ibu mengenai ASD. Hal tersebut dapat lebih mempermudah ibu untuk memahami ASD sehingga dapat menerima keadaan anak ASD dalam keluarga.

Akan tetapi, saat ini strategi koping yang digunakan oleh ibu adalah strategi koping pola I. Ibu merasakan bahwa dukungan dari keluarga ternyata lebih dapat membantu contoh meringankan beban dalam merawat anak ASD. Dukungan keluarga ternyata menjadikan ibu menjadi lebih optimis, bersemangat dan selalu bersyukur, serta lebih percaya diri sehingga membantu ibu meringankan beban yang dirasakan dalam merawat anak ASD. Selain itu, kerjasama dari semua anggota keluarga dalam merawat anak ASD sangat diperlukan untuk meningkatkan kemampuan dan kemandirian anak ASD.

Faktor yang Berhubungan dengan Dukungan Keluarga, Pengetahuan dan Persepsi Ibu terhadap Anak ASD

Hasil analisis hubungan antara karakteristik keluarga dan anak dengan dukungan keluarga menunjukkan bahwa usia ibu berhubungan negatif signifikan dengan dukungan keluarga ( $r$-koefisien= $-0,413, p$-value $=0,021$ ) begitu pula usia suami berhubungan negatif signifikan dengan dukungan keluarga ( $r$-koefisien= $-0,387, p$-value $=0,031)$. Semakin muda usia ibu dan suami, dukungan keluarga yang diperoleh semakin kuat. Namun, tidak terdapat hubungan yang signifikan antara karakteristik keluarga dan anak dengan pengetahuan ibu mengenai ASD. Sementara itu, usia anak ASD berhubungan negatif signifikan dengan persepsi ibu terhadap anak ASD (r-koefisien $=-0,464, \quad p$-value $=0,008)$. Begitu pula lama terapi berhubungan negatif signifikan dengan persepsi ibu ( $r$-koefisien $=-0,389, \quad p$-value $=0,03$ ). Semakin muda usia anak ASD dan semakin singkat anak ASD di terapi, persepsi ibu terhadap anak ASD cenderung positif.

\section{Faktor yang Berhubungan dengan dengan Strategi Koping Ibu}

Karakteristik keluarga, dukungan keluarga, pengetahuan serta persepsi ibu terhadap anak ASD ternyata tidak berhubungan signifikan dengan strategi koping yang digunakan oleh ibu dalam upaya meringankan tekanan yang dihadapi dalam merawat anak ASD. Hal ini diduga bahwa strategi koping yang diterapkan oleh ibu berhubungan dengan kepribadian ibu dan tingkat perkembangan anak ASD, dimana variabel tersebut tidak diteliti dalam penelitian ini.

\section{KESIMPULAN DAN SARAN}

\section{Kesimpulan}

Hampir separuh ibu (45,2\%) memperoleh dukungan keluarga yang kurang kuat. Namun lebih dari separuh ibu $(51,6 \%)$ memiliki pengetahuan yang baik mengenai ASD dan memiliki persepsi positif terhadap anak ASD $(54,8 \%)$.

Strategi koping ibu yang banyak digunakan pada saat pertama kali mengetahui anak ASD adalah memahami situasi medis melalui komunikasi antar orang tua dan konsultasi dengan staf medis $(54,8 \%)$ (pola III). Akan tetapi, strategi koping yang digunakan oleh ibu pada saat ini adalah strategi koping pola I yaitu mempertahankan keutuhan keluarga, kerjasama, dan situasi optimis $(54,8 \%)$ dan tidak ada yang ibu yang menggunakan strategi koping pola II yaitu memelihara dukungan sosial, kepercayaan diri, dan stabilitas psikologis. Hasil uji statistik menunjukkan bahwa terdapat perbedaan signifikan antara strategi koping saat pertama dengan strategi koping yang digunakan ibu pada saat ini.

Dukungan keluarga relatif lebih tinggi pada ayah dan ibu dengan umur yang lebih muda ( $r=-0,413$ pada ibu dan $r=-0,387$ pada ayah). Sementara pengetahuan ibu tentang ASD tidak berhubungan dengan karakteristik keluarga maupun anak. Persepsi ibu tentang ASD semakin baik pada anak yang lebih muda $(r=-0,464)$ dan pada anak yang baru mengikuti terapi $(r=-0,389)$. Karakteristik keluarga dan anak, dukungan keluarga, pengetahuan 
serta persepsi ibu tidak berhubungan signifikan dengan strategi koping.

\section{Saran}

Untuk penelitian selanjutnya disarankan untuk mengambil contoh secara acak dari populasi yang besar dan berasal dari karakteristik keluarga yang beragam. Untuk orang tua yang mungkin belum bisa menerima anak ASD atau memiliki persepsi negatif terhadap anak ASD di dalam keluarga maka diperlukan suatu strategi koping yang dapat membantu ibu dalam menerima anak ASD. Strategi koping tersebut antara lain dengan berdoa dan bersyukur kepada Tuhan YME, meningkatkan kepercayaan diri dan mengontrol emosi sehingga menciptakan rasa optimis dalam merawat anak ASD, mendapatkan dukungan dari semua anggota keluarga, serta selalu mencari informasi dan berkonsultasi dengan dokter, terapis dan orang tua yang juga memiliki anak ASD.
Diperlukan pula kasih sayang yang tulus dalam merawat dan melakukan terapi dan pengobatan medis pada anak ASD.

\section{DAFTAR PUSTAKA}

Dumas JE, Nilsen WJ. 2003. Abnormal Child and Adolescent Psychology. Boston: Allyn and Bacon.

Kelana A, Elmy DL. 2007. Kromosom Abnormal Penyebab Autisme [terhubung berkala]. www.gatra.com/artikel.php?id=1028 73. [28 Agustus 2007].

McCubbin HI, Thompson Al, editor. 1987. Family Assesment Inventories for Research and Practice. Madison: University of Winconsin.

Tobing LE. 2004. Stres, Coping, and Psychological Distress of Mother of Children with Pervasive Development Disorders. Psychology Journal. [15 Januari 2008].

\footnotetext{
*Korespondensi :

Departemen IImu Keluarga dan Konsumen

Fakultas Ekologi Manusia IPB

JI. Lingkar Kampus IPB Dramaga 16680

Telp : +62-2518628303

Email : tutimartianto@yahoo.com
} 